Pạiéia, 2002, 12(22), 97-101

\title{
CONSCIÊNCIA, INTENCIONALIDADE E INTERCORPOREIDADE ${ }^{1}$
}

\author{
Nelson Ernesto Coelho Junior
}

\begin{abstract}
RESUMO: Este texto tem por objetivo situar e discutir consciência, intencionalidade e intersubjetividade nas teorias fenomenológicas de Edmund Husserl e Maurice Merleau-Ponty, no contexto de um debate sobre a Teoria das Duas Consciências de Arno Engelmann. São propostas três questões ao professor Arno Engelmann.
\end{abstract}

Palavras chaves: Consciência, fenomenologia, intersubjetividade, intercorporeidade.

\section{CONSCIOUSNESS, INTENTIONALITY AND INTERCORPOREALITY}

\begin{abstract}
S: The aim of this paper is to situate and discuss consciousness, intentionality and intersubjectivity in Edmund Husserl's and Maurice Merleau-Ponty's phenomenological theories, in the context of a debate about Arno Engelmann's Theory of the Two Consciousness. Three questions are proposed to professor Arno Engelmann.
\end{abstract}

Key words: Consciousness, phenomenology, intersubjectivity, intercorporeality.

Arno Engelmann pertence a uma categoria rara de mestres e colegas na área da Psicologia. Extremamente discreto em seu fazer, surpreende nos sempre com comentários inesperados e plenos de sabedoria e humor. Reconhecido por seu extremo rigor e seriedade na pesquisa e no ensino da Psicologia há quatro décadas, mantém sua generosa disponibilidade no contato com alunos e colegas que o procuram constantemente no Instituto de Psicologia da Universidade de São Paulc. Sempre acreditei que sua importante obra e suas qualidades como grande pesquisador e professor de Psicologia precisariam ser destacadas e ainda mais valorizadas. E assim, eu não poderia ter tido outra reação que a de enorme felicidade quando soube pelo próprio Professor Arno que iria se realizar o presente curso, nesse segundo semestre de 2001, aqui em Ribeirão Preto. Portanto, quando recebi o convite do Professor José Lino Bueno para vir participar desta nossa atividade de hoje, só pude acrescentar à felicidade o prazer de ainda ter a honra de testemunhar e de alguma forma, contribuil, para esse importante evento dedicado à obra e às idéias de Arno Engelmann.

Considerando as extraordinárias contribuições

\footnotetext{
1 Artigo recebido para publicação em 07/2002; aceito em 08/2002. : Endereço para correspondência: Nelson Ernesto Cuelho Júnior. Instituto de Psicologia, USP, Av. Prof. Lúcio Martins Rodrigues. Trav.5, Bloco 17. Cidade Universitária, São Paulo, SP, CEP. 05508-900. E-mail: patnelco@uol.com.br.
}

do Prof. Arno para o estudo da Consciência, e seu invejável estilo de exposição, senti-me, de imediato, diante das mais difíceis das tarefas que me foram propostas nestes meus anos na Universidade. Como fazer jus às idéias e formulações propostas pelo Prof. Arno sobre o tema da Consciência, como favorecer um debate construtivo em torno de um tema de tão difícil apreensão? Afinal, é quase consenso que a consciência é ao mesmo tempo a presença mais imediata que possuímos e a entidade menos tangível, a mais inescrutável da existência humana. De Descartes a autores contemporâneos como Dennet e Chalmers, o estudo da consciência tem criado fascinação e impasses. Sobre o que falar, como contribuir para o debate?

Minha opção acabou sendo tratar do tema da Consciência em dois autores que venho estudando nos últimos 20 anos e que sei que pertencem ao campo de referências do Prof. Arno. São os filósofos fenomenólogos Edmund Husserl (1859-1938) e Merleau- Ponty (1908-1961). A exposição de algumas das idéias de Husserl visa apenas preparar uma exposição das idéias de Merleau-Ponty que, como se sabe, foi um filósofo apaixonado pela Psicologia da Gestalt e pela fenomenologia de Husserl desde seus primeiros anos de pesquisa e que soube conciliar essa paixão com o interesse crescente pela psicanálise nos anos de sua maior maturidade intelectual. Merleau-Ponty produziu um pensamento original e 
bastante instigante, que parte da noção de consciência perceptiva, caminha por uma peculiar noção de corpo vivido para desembocar, em seus últimos textos, em uma particular noção de intercorporeidade. Entendo que os temas tratados por Merleau-Ponty, embora possam abrir inúmeras outras questões que poderiam nos afastar do objeto principal de nosso debate, incidem diretamente sobre diversos aspectos dos textos do Prof. Arno Engelmann discutidos no presente curso. Assim, farei ao final da exposição três questões que têm como origem o que os textos de Arno Engelmann provocaram em minha reflexão ao entrarem em contato com uma trajetória de investigação filosófica apoiada nas proposições de Husserl sobre a intencionalidade e nas de MerleauPonty sobre a intercorporeidade.

\section{Consciência Intencional em Husserl e Cons- ciência Perceptiva e Intercorporeidade em Merleau-Ponty}

O que é a consciência? Como se dá a relaçâo ou o acesso entre a consciência e o resto do mundo? E qual é a relação entre a consciência e o corpo? Quais são as formas possiveis de relação entre a minha consciência e a consciência de ưn outro ser humano? É possível, de fato, conceber-se uma experiência intersubjetiva (inter-consciências?) Estas questóes permeiam todo o trabalho do professor Arno Engelmann e são também questões fundantes para a tradição da fílosofia fenomenológica inaugurada por Edmund Husserl e largamente desenvolvida por Merleau-Ponty.

Não há como introduzir o tema da consciência na obra de Merleau-Ponty sem antes retomar as noções de consciência intencional e de intersubjetividade apresentadas por Husserl. Com isso, espero explicitar o quanto a noçã̃o de consciência na fenomenologia acaba por assumir contornos diferentes daqueles encontrados tanto na tradição filosófica moderna como, em função desta, na origem dos estudos psicológicos.

Como se sabe, a consciência não é concebida na fenomenologia como um em si, como algo independente do mundo, dos outros e dos objetos. A con- cepção de uma consciência intencional implica no fato da consciência ser sempre consciência de, consciência aberta ao mundo, sempre consciência de algo.

$\mathrm{O}$ conceito de intencionalidade (do latim intentio) foi primeiramente usado em filosofia pelos escolásticos para indicar o caráter representativo do objeto imanente em relação ao objeto exterior, e, portanto, para designar a consciência como luminosa, como tendo um sentido relativamente a esse objeto.

Brentano (1973), psicólogo e filósofo, professor de Husserl e Freud em Viena, a partir do texto dos escolásticos desenvolveu a noção de intencionalidade em relação aos atos psicológicos. Ele entendia que o fenômeno mental continha como característica exclusivamente sua um objeto dentro de si mesmo e, exemplificava, afirmando que no ódio, sempre algo é odiado, no amor, amado.

A partir dessas afirmações, Husserl incluirá, como idéia fundamental em sua fenomenologia a noção de intencionalidade, ainda que com outras conotações. Husserl apresenta a intencionalidade como sendo algo inerente ao ato de conhecimento, situando-a como sendo a característica destes atos de sempre se referirem a algo, implicarem em algum objeto de conhecimento:

"Pertence à essência das vivências de conhecimento (Erkentniserlebnisse) ter uma intentio, significar alguma coisa, referirse a uma objetividade". (Husserl, 1950, p.55)

Assim, o conhecimento para Husserl implica em uma consciência intencional, que não é consciência em si, mas sempre consciência de alguma coisa. Entre consciência e objeto não há mais um abismo intransponível, ou a necessidade de uma consciência que constitua seus objetos, ou ainda de objetos que constituam uma consciência, mas sim, uma intencionalidade, que é um movimento, se assim podemos descrever, entre uma consciência que só é, se aberta para os objetos, e objetos que se mostram, que se colocam enquanto intencionais à essa consciência. Obviamente, esses objetos não devem ser entendidos apenas como objetos externos que possuam um substrato sensível (Hylé).

"A palavra intencionalidade não signifi- 
ca outra coisa senão essa característica geral da consciência de ser consciência de alguma coisa, de implicar, na sua qualidade de cogito, o seu cogitatum em si mesmo". (Husserl, 1966. p. 28).

Ao mesmo tempo é preciso reconhecer que na fenomenologia de Husserl a noção de intersubjetividade ocupará lugar central em sua discussão sobre a possibilidade de se conhecer a experiência que temos de um outro, assim como do mundo objetivo, em geral. Coerente com a recusa em conceber a fenomenologia como um simples idealismo, Husserl reconhece que o outro, uma outra consciência, ou um outro ego existem independentes de minha consciência. Assim como o mundo físico, "objetivo", está aí, antes de mim e de minha consciência e independente dela, também um outro sujeito, uma outra subjetividade precisaria ser reconhecida como possuindo uma existência independente de mim. Por outro lado, em seu desenvolvimento da idéia de uma fenomenologia transcendental, Husserl não tem como evitar a afirmação de que não há como conhecer o outro diretamente, de forma imediata. Só sei do outro, só conheço o outro, ou outra consciência, outro ego, a partir de minha consciência intencional. Assim, o outro só me aparece através desta mediação, através das condições presentes de ter apenas consciência de meu ego como pertença inequívoca, como presença imediata. $O$ outro só existe, neste sentido da consciência intencional, como uma experiência de meu ego. Deste modo, é possível afirmar que no plano da consciência intencional, o mundo vivido é sempre o mundo vivido de cada um, singularmente considerado, embora sempre intencionalmente dirigido a um outro objeto ou a uma outra consciência. Portanto, a experiência de um sujeito não teria como ser remetida, enquanto condição constituinte, a um mundo vivido em comum, compartilhado com outros. Este é um dos problemas que se colocou desde o início para a filosofia fenomenológica de Husserl. Desenvolvimentos posteriores, no entanto, sugerem uma nova solução para o problèna, através de uma fenomenologia genética (e não estútica) voltada para o tema da constituição das experiências vividas, no mundo da vida, fortalecidos com a publicação dos inéditos de Husserl. Esta solução aparecerá atra- vés da investigação das experiências da corporeidade. Nesse plano, a subjetividade passaria à esfera da intersubjetividade, através de uma experiência coconstituinte, que pertence a todos e a ninguém em particular, o que abrirá o caminho para o trabalho de vários fenomenólogos posteriores.

Merleau-Ponty aprofundará tanto a noção husserliana de consciência intencional, como a de intersubjetividade. Ele nomeará a consciência aberta ao mundo, a consciência intencional de Husserl, de consciência perceptiva. $\mathrm{Na}$ filosofia de MerleauPonty a consciência já não pode mais mesmo ser entendida como soberana ou constituinte, nem como uma consciência que pudesse ser "externa" ou "estrangeira" ao mundo vivido. Não é mais, portanto, uma consciência que a partir de representações, legisla sobre o mundo e a experiência sem mais leválos em conta. Merleau-Ponty recusa, portanto, uma consciência que não seja sempre consciência de algo: "Cremos saber muito bem o que é 'ver', 'ouvir', 'sentír', porque desde há muito tempo a percepção já nos deu objetos coloridos ou sonoros. Quando queremos analisar a percepção, transportamos esses objetos à consciência. Cometemos o que os psicólogos chamam a 'experience error', ou seja, supomos, de um só golpe, em nossa consciência das coisas, o que sabemos estar nas coisas. Fazemos percepçăo com o percebido. E como o próprio percebido só é evidentemente acessível através da percepção, acabamos por não compreender, finalmente, nem um nem outro. Estamos presos ao mundo e não conseguimos nos destacar dele para passar à consciência do mundo. Se o fizéssemos, veríamos que a qualidade não é nunca sentida imediatamente e que toda consciência é consciência de alguma coisa." (Merleau-Ponty, 1945, p. 11).

Em seus textos iniciais, Merleau-Ponty tenta, ao máximo, situar a consciência no corpo e o corpo no mundo. Para ele já não basta falar, como Husserl, em consciência intencional, que consciência é sempre consciência de alguma coisa. Uma consciência como a proposta por Husserl ainda correria o risco de "fugir" do mundo e assim transformar o mundo em um simples correlato do pensamento, das representações, retornando assim, a uma filosofia idealista. O mundo e o corpo não foram criados pela consciência como também não a criaram. A consciência 
deve ser compreendida sempre como consciência perceptiva, consciência que mantém, na medida em que está ligada inextrincavelmente ao corpo, um permanente diálogo com o mundo: "No que concerne à consciência, temos que concebê-la não mais como uma consciência constituinte e como um puro serpara-si, mas como uma consciência perceptiva, como sujeito de um comportamento, como ser-no-mundo ou existência..." (Merleau-Ponty, 1945, p.404).

Consciência é consciência perceptiva, é serno-mundo, é existência. Pode-se, assim, apreender o difícil movimento de Merleau-Ponty, da tradição filosófica em que foi formado, onde a consciência, o pensamento, o cogito cartesiano são fundamentos quase intocáveis, em direção inicialmente a uma filosofia fenomenológica existencial e posteriormente, ao campo de uma ontologia do sensível.

Merleau-Ponty procura mostrar, metodicamente, que a relação do homem com o mundo se dá sempre, inicialmente, pela percepção, por uma relação direta corpo-mundo. Não toco uma mão-idéia, uma pedra-idéia, um mundo-idéia, toco com meu corpo o mundo. Se posso me pensar como sujeito (e essa é ainda uma concessão de Merleau-Ponty a uma filosofia da consciência), só posso fazê-lo como corpo vivido, como corpo no mundo.

Cabe agora comentar a posição de MerleauPonty quanto ao tema da intersubjetividade. Em seu ensaio de 1959, "O Filósofo e sua Sombra", MerleauPonty ampliará as concepções husserlianas e formulará uma possibilidade radical de compreensão da relação entre eu e o outro, não mais através das lịmitadas possibilidades de uma intersubjetividade concebida a partir da consciência intencional, mas sim a partir da experiência do corpo, propondo o campo da intercorporeidade: "Minha mão direita assistia ao surgimento do tato ativo em minha mão esquerda. Não é de maneira diversa que o corpo do outro se anima diante de mim quando aperto a mão de outro homem, ou quando o olho somente. Aprendendo que meu corpo é 'coisa sentiente', que é excitável- ele e não somente minha 'consciência' - preparei-me para compreender que há outros animalia e, possivelmente, outros homens. É preciso notar bem que nisto não há comparação, nem analogia, nem projeção ou introjeção. Se, apertando a mão de um outro homem. tenho a evidência de seu ser-aí, é porque ela se colo- ca no lugar de minha mão esquerda. No aperto de mãos, meu corpo anexa o corpo de outro numa 'espécie de reflexão' cuja sede, paradoxalmente, é ele próprio. Minhas duas mãos são 'co- presentes' ou 'co- existem' porque são as mãos de um só corpo; o outro aparece por extensão desta co- presença. Ele e eu somos os órgãos de uma só intercorporeidade. (...) Percebo primeiro uma outra 'sensibilidade' e somente a partir daí, um outro homem e um outro pensamento." (Merleau-Ponty, 1960, pp.212-213)

Preocupado com como formular teoricamente uma experiência sensível do mundo e, em particular, uma experiência sensível do outro que é sempre anterior ontologicamente à possibilidade de apreensão consciente que posso vir a ter de um outro, Merleau-Ponty escreve em sua nota de fevereiro de 1959, publicada postumamente em O Visivel e o Invisivel (1964):

"Fala-se sempre do problema do 'outro',
de 'intersujetividade' etc. Na realidade, o
que se deve compreender é, além das 'pes-
soas', os existenciais segundo os quais nós
as compreendemos e que são o sentido
sedimentado de todas as nossas experiên-
cias voluntárias e. involuntárias. Este in-
consciente a ser procurado, não no fundo
de nós mesmos, atrás das costas de nossa'
consciência', mas diante de nós como ar-
ticulaçóes de nosso campo." (Merleau-
Ponty,1964, pp. 233-234).

Restaria trabalhar um pouco de que forma compreendemos nesse contexto o uso merleaupontiano da noção gestaltista de campo e, também retomar o uso específico que Merleau-Ponty faz da noção de inconsciente. Mas este já seria o início de outro debate que nos levaria para muito longe de nosso interesse de hoje, de nosso encontro em torno da Teoria das Duas Consciências de Arno Engelmann. Gostaria de finalizar apontando que as duas últimas citações apresentadas visam explicitar as posições do último período da obra de Merleau-Ponty, em que uma filosofia originada na tradição das filosofias da consciência passa a se constituir como uma filosofia da intercorporeidade e do inconsciente. Esta é a transformação exigida por uma filosofia que bus- 


\section{Consciência 101}

ca estabelecer uma ontologia do sensível. Da transposição inicial de uma filosofia ainda presa à noção de consciência para a vivência perceptiva como experiência fundante do processo de conhecimento, e daí à elaboração particular das noções de intercorporeidade e de inconsciente, definido por ele finalmente como "o deixar ser, o sim inicial, a indivisão do sentir." (Merleau-Ponty, 1960, p.179)

\section{Questões}

Apresentadas as idéias que serviram de base para a minha reflexão, que serviram também como noções organizadoras de meu diálogo com os textos de Arno Engelmann, gostaria de propor três questões que visam a ampliação de nosso diálogo:

1. Professor Arno Engelmann, considerando a especificidade de sua Teoria das Duas Consciências, mas relembrando também as influências da Psicologia da Gestalt em seu trabalho, como você conceberia o lugar da noção fenomenológica da intencionalidade no contexto de suas proposições teóricas atuais?

2. Uma questão acompanhou-me na leitura de seus textos e, agora, gostaria de propô-la publicamente: se "uma consciência não pode conhecer outra consciência do mesmo modo que se conhece a si mesma" (Engelmann, 1997, p.30) não há então lugar em sua teorização das duas consciências para relações intersubjetivas em que a experiência do outro, com o outro, possa lógica e cronologicamente ser simultânea à minha experiência de mim mesmo?

3. E, na sequêencia desta última questão, gostaria ainda de perguntar se você considera que a proposição de Merleau-Ponty da noção de intercorporeidade de fato contribui para a nossa compreensão teórica do que seria a experiência da apreensão do outro em sua alteridade? E, em caso positivo, se essa experiência de fato deve ser considerada ontologicamente anterior e determinante de qualquer experiência consciente que eu possa vir a ter de um outro?

\section{Referências Bibliográficas}

Brentano; F. (1973). Psychology from an empirical Standpoint. (A Rancurrelo, D.B. Terrel \& L. McAlister, Trads.), Londres: Routledge and Kegan Paul.

Engelmann, A. (1997). Dois Tipos de Consciência: a busca da autenticidade. Psicologia USP, 8 (2), 25-67.

Husserl, E. (1950). Die Idee der Phänomenologie. Em: Husserliana II, La HaH Haye: Martinus Nijhoff.

Husserl, E. (1966). Meditations Cartésiennes, Paris: J. Vrin.

Merleau-Ponty, M. (1945). Phénoménologie de la Perception, Paris: Gallimard.

Merleau-Ponty, M. (1960). Signes, Paris: Gallimard.

Merleau-Ponty, M.(1964). Le Visible et L'Invisible, Paris: Gallimard.

Merleau-Ponty, M. (1968). Résumé de Cours, Collège de France, 1952-1960. Paris: Gallimard. 